\title{
"Maned Wolf in the Museum:" a Case Study on Learning Through Action
}

\author{
Emanuel Felipe Duarte ${ }^{1}$, Vanessa R. M. L. Maike ${ }^{1}$, M. Cecília C. Baranauskas ${ }^{1}$ \\ ${ }^{1}$ Institute of Computing - University of Campinas (UNICAMP) \\ Av. Albert Einstein, 1251 - Campinas - SP - Brazil \\ \{emanuel.duarte, vanessa.maike, cecilia\}@ic.unicamp.br
}

\begin{abstract}
Newer theories of cognition, together with novel ways of interacting with computers, allow us to revisit the idea of learning through action. In this paper, we explore, in an educational context, the use of the "maned wolf" interactive artifact. The artifact promotes a learning experience about the real animal, through the action of actively exploring its digital tangible replica. Our study included 5 teachers and 15 children, who independently discovered the (not initially obvious) artifact features. We discussed the technologies involved and applied an evaluation instrument of their emotional response. Results indicate that the activity was generally well-received and that our study informs a discussion that can revisit the long-standing concept of learning through action.
\end{abstract}

\section{Introduction}

In the context of Human-Computer Interaction (HCI) and inspired by the concept of ubiquitous computing [Weiser 1991], over two decades ago [Ishii and Ullmer 1997] envisioned what the authors named a Tangible User Interface (TUI). TUI contrasts with a classic Graphical User Interface (GUI) manipulated with keyboard and mouse (and, more recently, touchscreen), in the sense that technology is embedded in everyday physical objects and environment, allowing interaction to come into the real world, and going beyond the virtual. This kind of user interface, when applied in educational contexts, presents an opportunity to study how tangible digital artifacts work on the learning process [Istenic et al. 2013, Silva et al. 2013, Panaggio and Baranauskas 2017]. In particular, it is an invitation to revisit the concept of learning through action.

This is an idea that has been widely investigated and experimented in varied learning contexts. In this paper, we draw on the concept of enaction from cognitive science to better understand and characterize the role action has during the learning process, while someone is interacting with a digital artifact. The context we chose to work on is that of an interactive artwork that could be displayed in a museum, and therefore simultaneously touches the worlds of art, education, and technology. We wish to challenge the concept that museum exhibitions are not to be touched and that they are meant to have an unquestioned admiration [Dewey 1934]. In fact, John Dewey's concept of aesthetics informs our perspective on the relationship people have with art and with the kinds of artifacts we find in museums. According to the author:

When an art product once attains classic status, it somehow becomes isolated from the human conditions under which it was brought into being and from the human consequences it engenders in actual life-experience. When artistic objects are separated from both conditions of origin and operation in experience, a wall 
VII Congresso Brasileiro de Informática na Educação (CBIE 2018)

Anais do XXIV Workshop de Informática na Escola (WIE 2018)

is built around them that renders almost opaque their general significance, with which esthetic theory deals. [Dewey 1934, p. 3]

So extensive and subtly pervasive are the ideas that set Art upon a remote pedestal, that many a person would be repelled rather than pleased if told that he enjoyed his casual recreations, in part at least, because of their esthetic quality. The arts which today have most vitality for the average person are things he does not take to be arts: for instance, the movie, jazzed music, the comic strip, and, too frequently, newspaper accounts of love-nests, murders, and exploits of bandits. For, when what he knows as art is relegated to the museum and gallery, the unconquerable impulse towards experiences enjoyable in themselves finds such outlet as the daily environment provides. [Dewey 1934, p. 5-6]

Therefore, in this paper, we present a case study where we tried to break down the walls built around artistic objects. To do so, we proposed an experimental scenario, simulating a museum visit with an interactive art exhibit that needs to be touched. Following the TUI philosophy, this exhibit is a tangible digital artifact, meant for educational contexts, and built with low-cost materials and hardware. It bridges the virtual and physical worlds by providing multimedia information when sensors in the artifact are triggered.

This paper is structured as follows: in Section 2 we discuss the background of our research with a focus on the premise of learning through action. In Section 3 we present our case study, entitled "Maned Wolf in the Museum", in which we present the interactive artifact we used, the activity we conducted and the results we collected. In Section 4 we discuss our main findings and their implications with regard to their relationship with the concepts of enaction and learning through action. Lastly, in Section 5 we present our conclusions and directions for future work.

\section{Background: Learning Through Action}

In what can be considered a first characterization of what would later be known as the "enactive approach", [Dewey 1896] argues about how we do not experience the world in ordinary sequences of stimulus and responses. For example, imagine a child reaching for a candle and learning how the flame is hot and can burn. One could interpret the light as a stimulus and the movement of reaching for the fire as a response, or the heat from the fire as a stimulus with the response of a sudden movement of taking the hand off the flame after feeling pain. Dewey, however, describes how there is a more complex sensorimotor coordination taking place: "[...] it is the movement which is primary, and the sensation which is secondary, the movement of body, head and eye muscles determining the quality of what is experienced." [Dewey 1896, p. 358].

In a similar fashion, [Bruner 1964] proposed a sequence for the learning process, composed of three moments: the action-based (enactive), the image-based (iconic) and the language-based (symbolic). Bruner says that these moments appear for a child in this particular order. However, based on their own observations, [Francis et al. 2016] argue that the three stages do not develop sequentially in time, nor are distinct from one another. Instead, the authors claim they are co-occurring and co-dependent, which is coherent with the sensorimotor coordination described by Dewey. In a way, this vision is also similar to what [Varela et al. 1993] described as "laying down a path in walking", i.e., we construct our understanding as we go, through bodily processes, such as walking, gesturing or interacting with others. In this sense, there is also the idea of "enactive 
VII Congresso Brasileiro de Informática na Educação (CBIE 2018)

Anais do XXIV Workshop de Informática na Escola (WIE 2018)

metaphors" [Gallagher and Lindgren 2015], metaphors we act out instead of simply ingesting them from a text. For instance, when an infant picks up a banana and pretends it is a phone, the action of picking up the banana and placing it by her ear is a way of treating the banana metaphorically. Furthermore, the infant enacts a metaphor built on her previous experiences with phones, and on her perception of the banana's shape.

All of these perspectives are somehow consistent with how [Varela et al. 1993] describe cognition, as something that cannot be entirely contained inside the brain; the body and the environment are an essential part of this equation. In a definition that is purposely circular to highlight the concept of co-origination of organism and world, the so-called "enactive approach" consists of two points:

(1) perception consists in perceptually guided action and (2) cognitive structures emerge from the recurrent sensorimotor patterns that enable action to be perceptually guided. [Varela et al. 1993, p. 173].

Considering that the context of our work touches the complex and elusive world of art through the concept of interactive art, the work of [Dewey 1934] on aesthetics might offer an insight into how we can apply the concept of enaction in our work. The author highlights the importance of a coordination between perception and action to describe art not as something static and pre-given, but as an experience that is enacted:

In order to understand the esthetic in its ultimate and approved forms, one must begin with it in the raw; in the events and scenes that hold the attentive eye and ear of man, arousing his interest and affording him enjoyment as he looks and listens [...] The sources of art in human experience will be learned by him who sees [...] the zest of the spectator in poking the wood burning on the hearth and in watching the darting flames and crumbling coals. [...] he is none the less fascinated by the colorful drama of change enacted before his eyes and imaginatively partakes in it. He does not remain a cold spectator. [Dewey 1934, p. 4-5]

\section{Case Study: "Maned Wolf in the Museum"}

Our case study took place at the Programa de Desenvolvimento e Integração da Criança e do Adolescente (PRODECAD). Located on the campus of the University of Campinas (UNICAMP), it is a space that offers complementary education to children from 4 to 14 years old after regular school hours. Furthermore, our study is part of a project approved by the university's research ethics committee under the number 32213314.8.0000.5404. In August 2017, we conducted an activity named "Maned Wolf in the Museum", which was conducted with two separate groups. The first group was composed of 7 teachers, all women between ages 40 to 53 years old. The second group had 15 children, 5 girls, and 10 boys, with ages from 8 to 11 years old. The entire activity was documented by video and photos. This separation is a convention already adopted in our research project, in other activities that were conducted in this location.

We introduced the activity by informally asking the participants if they were already familiar with the maned wolf (a wild canid from South America, also common in the city of Campinas), and most of them answered yes. Then, we talked about the experience of visiting a museum, which can be fun, but with the downside that visitors are usually not allowed to touch things. Finally, we explained that we would simulate a visit to a museum, but with an exhibit that people are allowed to freely explore and touch. 
VII Congresso Brasileiro de Informática na Educação (CBIE 2018)

Anais do XXIV Workshop de Informática na Escola (WIE 2018)

Such exhibit is the interactive maned wolf, an adaptation of one of the results of a project named InterArt, where undergraduate students were asked to create interactive artworks [Duarte and Baranauskas 2018]. The interactive maned wolf was designed for educational museums, and the students made it out of thin cardboard and other relatively inexpensive craft materials. However, particularly for this activity, researchers covered the original cardboard with a fabric that resembles fur, as can be seen in Figures 1 and 2. In terms of hardware, the artifact is controlled by an Arduino-compatible NodeMCU 1.0 ESP8266 development board with built-in Wi-Fi. The maned wolf's eyes are semitransparent spheres, with a white LED in each one that glows constantly. Some parts of the wolf (head, body, leg, and tail) have push-buttons that, when pressed, send a signal to the microcontroller, which forwards this signal through Wi-Fi to a computer located in the same room. This exchange of messages is managed through a protocol named Message Queuing Telemetry Transport (MQTT), appropriate for quick communications between everyday objects. In turn, the computer is responsible for presenting the information that corresponds to the button that was pressed. Such information includes image, sound, and text. In a similar fashion, there is a proximity sensor on the top of the wolf's head, meant to detect attempts to pet the wolf. When petted, for a few seconds the white LED behind the eyes turn off, and red ones turn on. In addition, the computer emits barking sounds, and then the informational text and voice explain that such behavior is because the wolf is a wild and dangerous animal. We relied on relatively low-cost hardware and craft materials. Besides an ordinary computer with a web browser, the electronic components used cost approximately US $\$ 20.00$ already considering local availability and taxes. Hypothetically, this value could be lowered to around US\$5.00 if it was possible to directly import components from China without additional taxes.

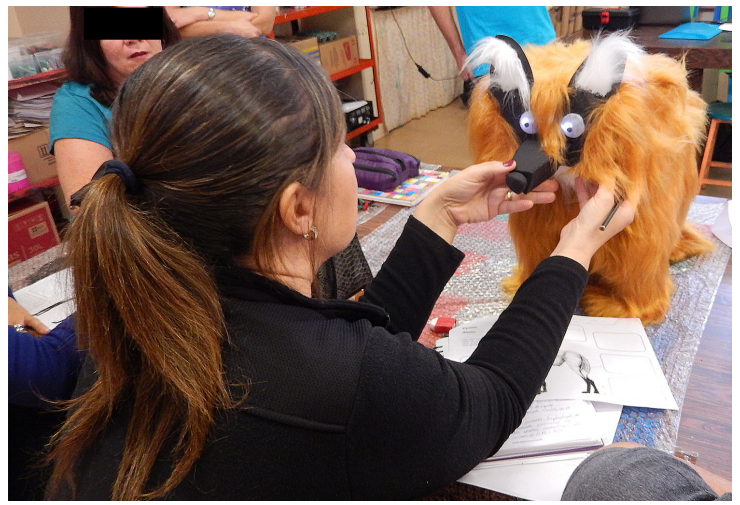

Figure 1. Teachers exploring the interactive maned wolf.

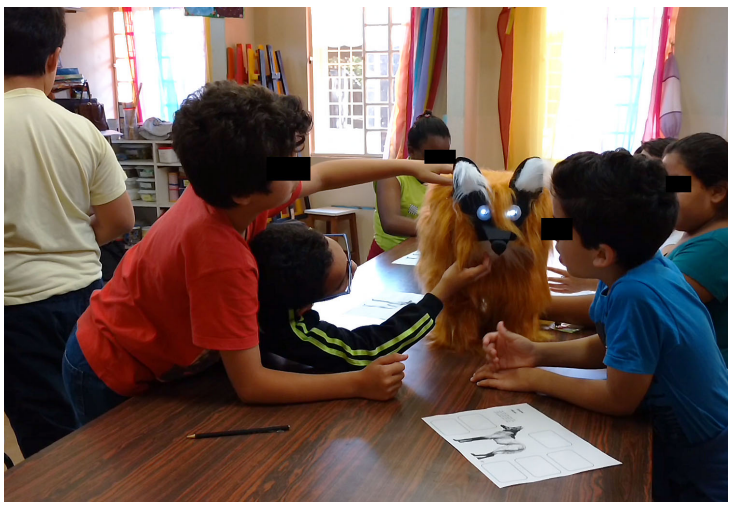

Figure 2. Children exploring the interactive maned wolf.

We asked the participants to freely explore the interactive maned wolf for about 15 minutes. They were provided with a paper containing an illustration of a maned wolf, and some empty boxes to fill in information that they learned while interacting with the artifact. In particular, the children were organized into two groups of 7 and 8 children respectively, so that while one group interacted with the artifact, the other waited outside the room, making drawings of the maned wolf. A sample of these drawings is illustrated in Figure 3. After the free exploration of the artifact ended, we conducted a conversation about what technologies the participants imagined were present in the interactive maned wolf. After we gathered their guesses, we gave them a brief explanation of the actual 
VII Congresso Brasileiro de Informática na Educação (CBIE 2018)

Anais do XXIV Workshop de Informática na Escola (WIE 2018)

hardware, and allowed them to look "under the hood". This was possible because the wolf's body has a lid, so we can open it like a shoe box and look at the hardware and wires inside. We finished the activity by applying an evaluation instrument. We used the Self-Assessment Manikin (SAM) [Bradley and Lang 1994], which the participants were already familiar with from previous activities. The SAM is a non-verbal pictorial instrument based on the Pleasure, Arousal, Dominance (PAD) emotional state model, and it is intended to allow people to express their feelings on these three dimensions, towards something like an artifact or even an experience (in this case, their answer was regarding the entire activity). The evaluation instrument was also complemented with the following two open questions answered in writing: "What did you like the MOST?" and "What do you like LEAST?".
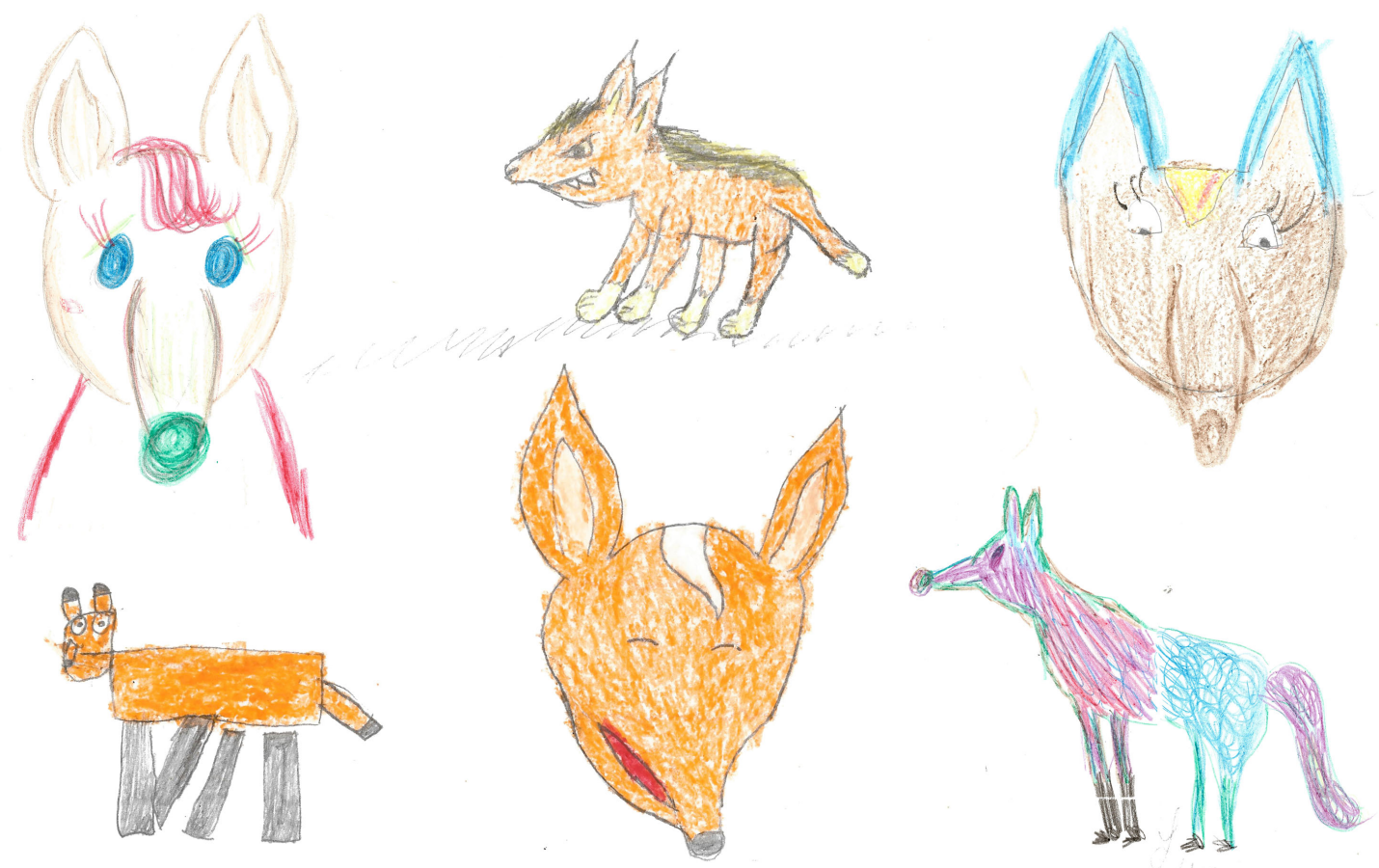

Figure 3. Sample of maned wolf drawings from the children.

\subsection{Results}

Our main results are: 1) the behaviors of the participants while interacting with the artifact; 2) the responses of the participants when imagining what kind of technologies are behind the artifact and making sense of how it works; and 3) the feedback from the SAM instrument and the participants' answers for what they liked most and least.

\subsubsection{Interaction Behavior}

Regarding the behavior while interacting with the artifact, both teachers and children were initially hesitant to take the first step. This was expected as we intentionally did not explain what the interactive maned wolf could do, and the digital features and means of interaction of the artifact were not clear because the "fur" conceals the wolf's buttons. 
VII Congresso Brasileiro de Informática na Educação (CBIE 2018)

Anais do XXIV Workshop de Informática na Escola (WIE 2018)

However, when someone starts touching and investigating the wolf and discovers, for instance, that there are buttons on it, the others around her are more inclined to investigate it together, leading to a social activity. Every group inevitably discovers that pressing a button triggers a multimedia response on the computer. After this discovery, some participants were interested in carefully pressing each button at a time and strictly writing down the information to fill in the empty boxes on provided paper - the one with an illustration of the maned wolf. Other participants, however, were first concerned with pressing all the buttons before writing anything. In fact, some children barely wrote anything because they were very entertained with interacting with the artifact. One aspect that took longer to be discovered was the proximity sensor in the head. As people, particularly children, interacted with the wolf, they would trigger the sensor without realizing it, and they would be surprised by the wolf becoming angry. After the first time this event was triggered, some children became especially interested in finding out how to make the wolf angry. After discovering how it worked, they would playfully do it repeatedly.

\subsubsection{Making Sense of Technology}

With respect to imagining what kind of technologies are behind the interactive maned wolf, it was already obvious for everyone that there were buttons. However, the working of the proximity sensor in the head was still elusive even for the kids who playfully activated it repeatedly. The participants also noticed that there was some kind of communication between the artifact and the computer displaying images and sounds. It was clear that this communication was wireless, as the maned wolf is self-contained, i.e., there are no cables coming out of it, and participants could freely pick it up and move it without interfering with its operation. When trying to figure out how the communication works, most participants did not guess anything beyond some kind of wireless signal, but one teacher, in particular, conjectured that there was a smartphone inside the "belly" of the wolf. When we opened the lid and revealed the inside of the wolf, we showed how the proximity sensor could be triggered without touching it, and how everything was connected to a microcontroller with Wi-Fi connection and powered by a battery. One child, when looking inside the wolf and seeing wires and electronic components, said surprised: "Wow! He is all robotic!".

\subsubsection{Evaluation Instruments}

With regard to SAM, Tables 1 and 2 show the responses for each participant. Blank fields indicate that the participant did not give a score for that dimension. The results for "pleasure" indicate that the activity was considered pleasurable and enjoyable by all the participants, and the results for "arousal" indicate that they were all also fairly excited about it. The results for "dominance", in turn, were lower when compared to the other two dimensions, although still relatively high. These lower values indicate that for teachers and children alike, not every participant felt entirely in control during the activity. Proportionally, however, more children felt in control when compared to teachers.

For the open questions about what they liked and disliked, the teachers highlighted that they liked the engineering and dynamic creativity of the activity, the interactivity, and 
VII Congresso Brasileiro de Informática na Educação (CBIE 2018)

Anais do XXIV Workshop de Informática na Escola (WIE 2018)

the sensory experience. They also praised how the wolf can be used by people with disabilities, since a blind person, for instance, can still interact with it using touch to find the buttons - just like sighted people - and hear the audio feedback. For things they did not like, only one teacher noted that she would like the wolf to walk and wag the tail. The children, in turn, highlighted the maned wolf artifact itself, and how they were able to see, learn, touch and draw it. For things they did not like, most children wrote "nothing". However, two of them wrote that they did not like that they had to work as a group, and one child reported that he did not like to have to draw the maned wolf. These are literal quotes from the participants (translated from Portuguese):

Participant \#4, teacher, liked: "The structure of the wolf was very interactive, providing much information through the sensory experience (touch) in the plush animal"

Participant \#5, teacher, liked: "A very interesting activity with a lot of interactivity and creativity"

Participant \#14, child, liked: "I liked to touch the maned wolf"

Participant \#21, child, liked: "Of everything. To draw the maned wolf and to write about the maned wolf"

Participant \#13, child, disliked: "Working with the group"

Table 1. SAM results from the teachers.

\begin{tabular}{cccc}
\hline Participant & Pleasure (from 1 to 9) & Arousal (from 1 to 9) & Dominance (from 1 to 9) \\
\hline$\# 1$ & 9 & 9 & 7 \\
$\# 2$ & 9 & 9 & 7 \\
$\# 3$ & 9 & 7 & 5 \\
$\# 4$ & 9 & 7 & 5 \\
$\# 5$ & 9 & 9 & 9 \\
$\# 6$ & 9 & 9 & 9 \\
$\# 7$ & 9 & 9 & $\mathbf{9 , 7}$ and $\mathbf{5}$ \\
\hline Mode & $\mathbf{9}$ & $\mathbf{9}$ & \\
\hline
\end{tabular}

\section{Discussion}

With regard to the kind of interaction that the artifact evokes, we do not consider problems neither the concealment of the wolf's buttons nor the ensuing uncertainty towards how to interact with it. We find that the exploratory nature of the artifact plays an important role in its educational intention. In this sense, the interactive maned wolf is not simply an exotic keyboard in which people press keys to see what happens; it is a mystery waiting to be solved. Being able to freely touch and investigate the artifact transforms the very act of discovering that there are buttons on it as important as finding out what the button does when pressed. Such freedom is consistent with the enactive approach presented in Section 2. While children and teachers explore the maned wolf, they make sense of how the artifact works. The sensorimotor coordination, in this case, involves the hands and eyes to touch the wolf, the head to turn and look at the computer screen, and the ears to 
VII Congresso Brasileiro de Informática na Educação (CBIE 2018)

Anais do XXIV Workshop de Informática na Escola (WIE 2018)

Table 2. SAM results from the children.

\begin{tabular}{cccc}
\hline Participant & Pleasure (from 1 to 9) & Arousal (from 1 to 9) & Dominance (from 1 to 9) \\
\hline$\# 8$ & 9 & 9 & 9 \\
$\# 9$ & 9 & 9 & 9 \\
$\# 10$ & 9 & 9 & 7 \\
$\# 11$ & 9 & 9 & 7 \\
$\# 12$ & 9 & 7 & 5 \\
$\# 13$ & 7 & 7 & 7 \\
$\# 14$ & 9 & 8 & \\
$\# 15$ & 9 & 9 & 4 \\
$\# 16$ & 9 & 8 & 9 \\
$\# 17$ & 9 & 6 & 8 \\
$\# 18$ & 9 & 8 & 8 \\
$\# 19$ & 8 & 9 & 8 \\
$\# 20$ & 8 & 9 & 4 \\
$\# 21$ & 9 & 7 & 9 \\
$\# 22$ & 8 & $\mathbf{9}$ & $\mathbf{9}$ and 8 \\
\hline Mode & $\mathbf{9}$ & & \\
\hline
\end{tabular}

listen to the audio information. All of this happens simultaneously, and goes on as one act feeds the other; the multimedia feedback makes them want to explore more of the wolf, so they keep touching it to find other buttons and then triggering other audio and visual information. This loop resembles the one described by [Varela et al. 1993], where the perceptually guided action is enabled by recurrent sensorimotor patterns, which make cognitive structures emerge and, hence, allow action to be perceptually guided. In this sense, the social component was crucial in this activity, despite some of the children not enjoying it. Taking a first step to interact with the maned wolf was usually slow, but once one person started exploring the artifact, others got excited and wanted to join in. In this case, one person has their action perceptually guided by the cognitive structures that emerge from seeing another person act; such exchange can go back and forth as long as they are all present and involved in the interaction.

In a similar manner, asking participants to guess what are the technologies involved in the artifact, is part of a learning process that goes beyond understanding what the artifact does; it entails making sense of how it works. We can see Bruner's three moments happening at the same time: there is action in exploring the wolf and in looking under the hood to see the hardware; the spatial distribution of the wolf and its sensors, along with the images displayed on the computer screen constitute the iconic stage; finally, understanding that pressing a button or petting the wolf has a consequence, and imagining there is a wireless communication between the wolf and the computer are all part of the symbolic phase. For both teachers and children, this experience was interesting to show them that technological devices are not "magical black boxes". By allowing them to explore the artifact, and then showing its inner workings, and illustratively associating it with already known devices or concepts, we gave them a chance to start a more active and informed relationship with technology.

In turn, the results from SAM indicate that both teachers and children, in different 
VII Congresso Brasileiro de Informática na Educação (CBIE 2018)

Anais do XXIV Workshop de Informática na Escola (WIE 2018)

ways, found the activity to be pleasurable, and showed some kind of excitement towards it. During the activity, this was observed by how the teachers calmly explored the wolf, discussed its educational qualities and shared their experiences in museums (and the recurrent "do not touch" policy). The children, however, were extremely excited about the prospect of freely exploring the artifact, and besides the physical exploration, some of them explicitly showed interest in learning new information about the animal and writing it down. As for SAM's dominance dimension, most results are high. The lower numbers in comparison with the other two dimensions also highlight what we consider to be an important aspect of our activity: when we work with an artifact such as the interactive maned wolf, inviting towards exploration and somehow elusive, we do not expect (nor want) people to feel completely "in control" of it. The artifact is a mystery that requires some amount of uncertainty (and sometimes discomfort) to be deciphered, and we conjecture that this very uncertainty and elusiveness corroborates to the high levels of pleasure and arousal in the other two dimensions.

Overall, interacting with the maned wolf was not only a technological and educational experience but also a social activity, as the participants explored it together. One challenge perceived in our study was devising means to allow everyone to participate equally in the exploration of the interactive artifact. This is important, as some kids are more prone to take control of the activity, which may refrain shyer children from joining in. This is probably why two children reported that they did not like having to work as a team. However, to simulate a museum scenario, the activity had to include the social component of collective exploration. As discussed earlier in this section, the social component emerged as an important part of the enactive learning process. In this sense, it would be beneficial to investigate how the artifact could promote more participation, and perhaps empathy, among children.

\section{Conclusion}

In this paper, we gathered a brief theoretical background on enactivism situated in an educational context and used it no analyze our case study. We simulated a museum exhibit that, unlike the conventional approach, not only can be, but must be touched. The exhibit consisted of a tangible digital version of the maned wolf. This interactive artifact had sensors hidden under its artificial fur, and part of the interaction involved discovering where the sensors were, and what each of them did. Then, in our case study, we observed children and teachers using touch, vision, and hearing to explore and learn with the artifact, using a sensorimotor coordination similar to what the enactive approach describes. We also noted the importance of the social component of a collective exploration. Although some children complained about not fully enjoying the experience because of their colleagues, our evaluation indicated that participants were excited and satisfied with the activity, even though some of them did not feel completely in control. This is expected because the artifact requires some discovery, which can evoke unpredictability. We do not see this as a negative aspect because the unpredictable exploration highlights the enactive approach in the way children and teachers interacted with the wolf.

For future work, we want to further mediate an even more active and informed relationship with technology for both teachers and children. Considering that the technologies used in this study allow plenty of customization and rapid prototyping, we find it plausible to consider that both teachers and students could further elevate themselves to 
VII Congresso Brasileiro de Informática na Educação (CBIE 2018)

Anais do XXIV Workshop de Informática na Escola (WIE 2018)

the role of technology co-designers. This could be achieved, for instance, by mediating their participation in the creation of a new version of the maned wolf interactive artifact, or even envisioning and building from scratch a novel artifact altogether. We also intend to further explore the social component afforded by the artifact, which was prominent in our analysis, leading towards investigation of the concept of a socioenactive system.

\section{Acknowledgments}

This study was financially supported by the National Council for Scientific and Technological Development (CNPq) grant \#306272/2017-2 and São Paulo Research Foundation (FAPESP) grants \#2015/16528-0, \#2015/24300-9 and \#2017/06762-0.

\section{References}

Bradley, M. M. and Lang, P. J. (1994). Measuring emotion: The self-assessment manikin and the semantic differential. Journal of Behavior Therapy and Experimental Psychiatry, 25(1):49 - 59 .

Bruner, J. S. (1964). The course of cognitive growth. American psychologist, 19(1):1.

Dewey, J. (1896). The reflex arc concept in psychology. Psychol. Rev, 3(4):357-370.

Dewey, J. (1934). Art as Experience. Minton, Balch \& Company, New York, NY, USA.

Duarte, E. F. and Baranauskas, M. C. C. (2018). Interart: Learning human-computer interaction through the making of interactive art. In Kurosu, M., editor, Human-Computer Interaction. Theories, Methods, and Human Issues, pages 35-54, Cham. Springer International Publishing.

Francis, K., Khan, S., and Davis, B. (2016). Enactivism, spatial reasoning and coding. Digital Experiences in Mathematics Education, 2(1):1-20.

Gallagher, S. and Lindgren, R. (2015). Enactive metaphors: Learning through full-body engagement. Educational Psychology Review, 27(3):391-404.

Ishii, H. and Ullmer, B. (1997). Tangible bits: Towards seamless interfaces between people, bits and atoms. In Proceedings of the ACM SIGCHI Conference on Human Factors in Computing Systems, CHI '97, pages 234-241, New York, NY, USA. ACM.

Istenic, S. A., Mara, C., and Matej, Z. (2013). Design-based research on the use of a tangible user interface for geometry teaching in an inclusive classroom. British Journal of Educational Technology, 44(5):729-744.

Panaggio, B. and Baranauskas, M. C. (2017). Explorando as possibilidades do sphero em um ambiente educacional. In Anais do XXIII Workshop de Informática na Escola (WIE 2017). Brazilian Computer Society (Sociedade Brasileira de Computação - SBC).

Silva, M., Roberto, R., and Teichrieb, V. (2013). Evaluating an educational system based on projective augmented reality. In Anais do XXIV Simpósio Brasileiro de Informática na Educação (SBIE 2013). Sociedade Brasileira de Computação.

Varela, F. J., Thompson, E., and Rosch, E. (1993). The Embodied Mind: Cognitive Science and Human Experience. Cognitive science: Philosophy, psychology. MIT Press, Cambridge, Massachusetts, United States.

Weiser, M. (1991). The computer for the 21st century. Scientific American, 265(3):94104. 